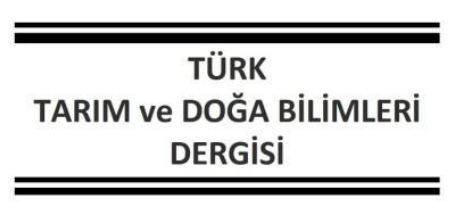

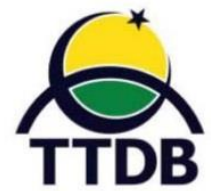

www.dergipark.gov.tr/turkjans

Araştırma Makalesi

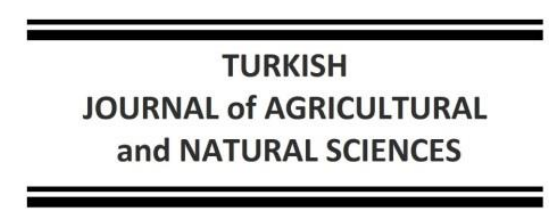

and NATURAL SCIENCES

\title{
Bir Besi Çiftliğinde Güneş Enerji Sisteminin Uygulanması ve Ekonomik Analizi
}

\author{
Nuri ORHAN ${ }^{1 *}$, Seda ŞAHIN ${ }^{1}$ \\ ${ }^{1}$ Selçuk Üniversitesi, Ziraat Fakültesi, Tarım Makineleri ve Teknolojileri Mühendisliği Bölümü, Konya \\ *Sorumlu Yazar: nuriorhan@selcuk.edu.tr
}

Geliş Tarihi: 22.10.2021 Düzeltme Geliş Tarihi: 09.01.2022 Kabul Tarihi: 13.01.2022

\section{Öz}

Enerji ihtiyacının maliyetini minimuma indirmek tarımsal işletmelerin kar payının arttırmasında katkı sağlamaktadır. Çiftlikler bu amaçla, enerji tüketimi fazla olan tarımsal üretim işlemlerini yerine getirebilmek için yenilenebilir enerji kaynakları olan biyoyakıt, güneş ve rüzgar enerjisinden yararlanmaktadır. Tarımsal üretimde özellikle de hayvan yetiştiriciliğinde daha kaliteli ve yüksek verime ulaşabilmek makineleşme ile doğru orantılıdır. Makineleşmeye bağıı olarak enerji tüketimi de artış göstermektedir. Günümüzde enerji maliyetinin yükselmesi, çiftçilerimizin gelirlerinin önemli bir bölümünü elektrik faturalarına ayırmasına sebep olmaktadır. Bu çalışmada, artan bu elektrik ihtiyacını karşılamak için Konya'da, bir büyük baş hayvan çiftliğinde güneş enerjisinin uygulanabilirliği ve işletmeye ekonomik getirisinin hesaplanması amaçlanmıştır. İ̧̧letmenin çatısına kurulan ve fotovoltaik panellerden oluşan güneş enerjisi sisteminin üreteceği elektrik hesaplamaları iki farklı yönteme göre yapılmıştır. Güneş panellerinden anlık ölçümler ve aylık güneşlenme süreleri dikkate alınarak yapılan hesaplama ile photovoltaic geographical information system (fotovoltaik coğrafi bilgi sistemi) hesaplamaları karşılaşııııımışıı. Yöntemler arasında \%3.7'lik bir fark bulunmuştur. İ̧̧letmenin çatııına kurulan güneş enerjisi sisteminin toplam maliyeti 1884600 TL olarak hesaplanmıştır. İ̧letmenin aylık elektriksel yükü 35746 kWh olarak belirlenmiştir. İşletmenin aylık ortalama olarak elektrik tüketimi 27881 TL, yıllık ise 334582 TL hesaplanmıştır. Güneş enerjisi sisteminin aylık elektrik üretim miktarı 21280 TL, yıllık ise 255368 TL'dir. Sistemin kendini amorti etme süresi yaklaşık 7.2 yıl hesaplanmıştır. Güneş enerjisi sisteminin yaklaşık 25 yıl ömrü olduğunu hesaba katıldığında geriye kalan 17.8 yıl sonunda işletmenin maliyetlerinde yaklaşık olarak 4.5 milyon TL azalmanın olacağı tahmin edilmektedir. Ayrıca işletmenin güneş enerjisi sistemi ile temiz enerji üretimi sayesinde, yıllık elektrik tüketim değerine eşdeğer $750142 \mathrm{~kg} \mathrm{CO} 2$ salınımı engellenmiş olacaktır. Bu işletme için güneş enerji sisteminin ekonomik bir yatıım olmasının yanı sıra elektrik üretimi bakımından $\mathrm{CO}_{2}$ salınımına sebep olmaması büyük bir avantajdır.

Anahtar kelimeler: Yenilenebilir enerji, Güneş enerjisi sistemi, Fotovoltaik panel, Besi çiftliği.

\section{Application and Economic Analysis of Solar Energy System in Breeding Farm}

\begin{abstract}
Minimizing the cost of energy needs also contributes to increasing the profit share of agricultural enterprises. For this purpose, farms benefit from renewable energy sources such as biofuel, solar and wind energy in order to carry out agricultural production processes with high energy consumption. Achieving higher quality and higher efficiency in agricultural production, especially in animal breeding, is directly proportional to mechanization. Energy consumption is also increasing due to mechanization. Today, the increase in energy costs causes our farmers to allocate a significant part of their income to electricity bills. In this study, it is aimed to calculate the applicability of solar energy and the economic return to the enterprise in a cattle farm in Konya to meet this increasing electricity demand. The electricity calculations to be produced by the solar energy system installed on the roof of the enterprise and consisting of photovoltaic panels were made according to two different methods. Photovoltaic geographical information system calculations were compared with the calculation made by taking into account instant measurements from solar panels and monthly sunshine
\end{abstract}


durations. A difference of $3.7 \%$ was found between the methods. The total cost of the solar energy system installed on the roof of the enterprise was calculated as $1884600 \mathrm{TL}$. The monthly electrical load of the enterprise has been determined as $35746 \mathrm{kWh}$. The monthly average electricity consumption of the enterprise is $27881 \mathrm{TL}$, and the annual average is $334582 \mathrm{TL}$. The monthly electricity production amount of the solar energy system is $21280 \mathrm{TL}$ and the annual amount is $255368 \mathrm{TL}$. The payback period of the system is approximately 7.2 years. If we take into account that the solar energy system has a lifespan of approximately 25 years, it is estimated that there will be a decrease of approximately 4.5 million TL in the operating costs at the end of the remaining 17.8 years. In addition, thanks to the clean energy production with the solar energy system of the enterprise, $750142 \mathrm{~kg}$ of $\mathrm{CO}_{2}$ emission equivalent to the annual electricity consumption value will be prevented. It is a great advantage for this enterprise that the solar energy system is an economic investment and does not cause $\mathrm{CO}_{2}$ emissions in terms of electricity production

Key words: Renewable energy, Solar energy system, Photovoltaic panel, Breeding farm.

\section{Giriş}

Tarımsal üretimin önemli bileşenlerinden biri de enerji ihtiyacıdır. Tarımsal üretim faaliyetleri içerisinde enerji tüketimi yüksek olan başlıca işlemler; tarımsal sulama, kurutma, sera ve hayvan barınaklarının ısıtma ve soğutulması ile süt sağım üniteleridir (Güler, 2014). Çiftlikler, enerji tüketimi fazla olan tarımsal üretim işlemlerini yerine getirebilmek için yenilenebilir enerji kaynakları olan biyoyakıt, güneş ve rüzgar enerjisinden destek almakta veya tamamını bu kaynaklardan sağlamaktadır. Bu yenilenebilir enerji kaynaklarının temel amacı temiz ve sürdürülebilir çevreye sahip olmak ve gelecek yıllara yaşanabilir bir ortam bırakmaktır (Karaağaç ve ark., 2020). Bu bağlamda Kyoto ve Montreal protokolleri birçok ülke tarafından imzalanarak yenilenebilir enerjinin bağlayıcı ve sürdürülebilir olması amaçlanmıştır.
Bölgesel koşullar tarım sektöründe yenilenebilir enerji kaynaklarının ekonomik kullanımını ve uygulama yöntemini etkilemektedir (Öztürk ve ark., 2010). Güneş enerjisi sistemleri için yıllık ortalama güneşlenme süresi ve coğrafi konumu bakımından en ideal yerlerden biri Türkiye'dir (Karaağaç ve ark., 2020). Türkiye'nin ortalama yıllık toplam güneş ışınım şiddeti 1527.4 $\mathrm{kWh} \mathrm{m}^{-2}$ olup günde yaklaşık 7.5 saat güneşlenme süresi de dikkate alındığında yıllık güneşlenme süresi ortalama 2724 saattir. Bir diğer ifadeyle günlük 4.24 $\mathrm{kWh} \quad \mathrm{m}^{-2}$ enerji üretimi gerçekleştirilebilir. Türkiye'nin güneş panelleri ile gerçekleştirebileceği ortalama elektrik üretim potansiyeli 600 bin $\mathrm{MW}$ gibi çok yüksek bir değerdir (Aksungur ve ark., 2013). Bu potansiyele sahip olan Türkiye'nin 2021 yılı Ağustos ayı itibarıyla elektrik enerjisi toplam kurulu gücünün \%7.5'u güneş enerjisinden sağlanmaktadır (Hakyemez, 2021).

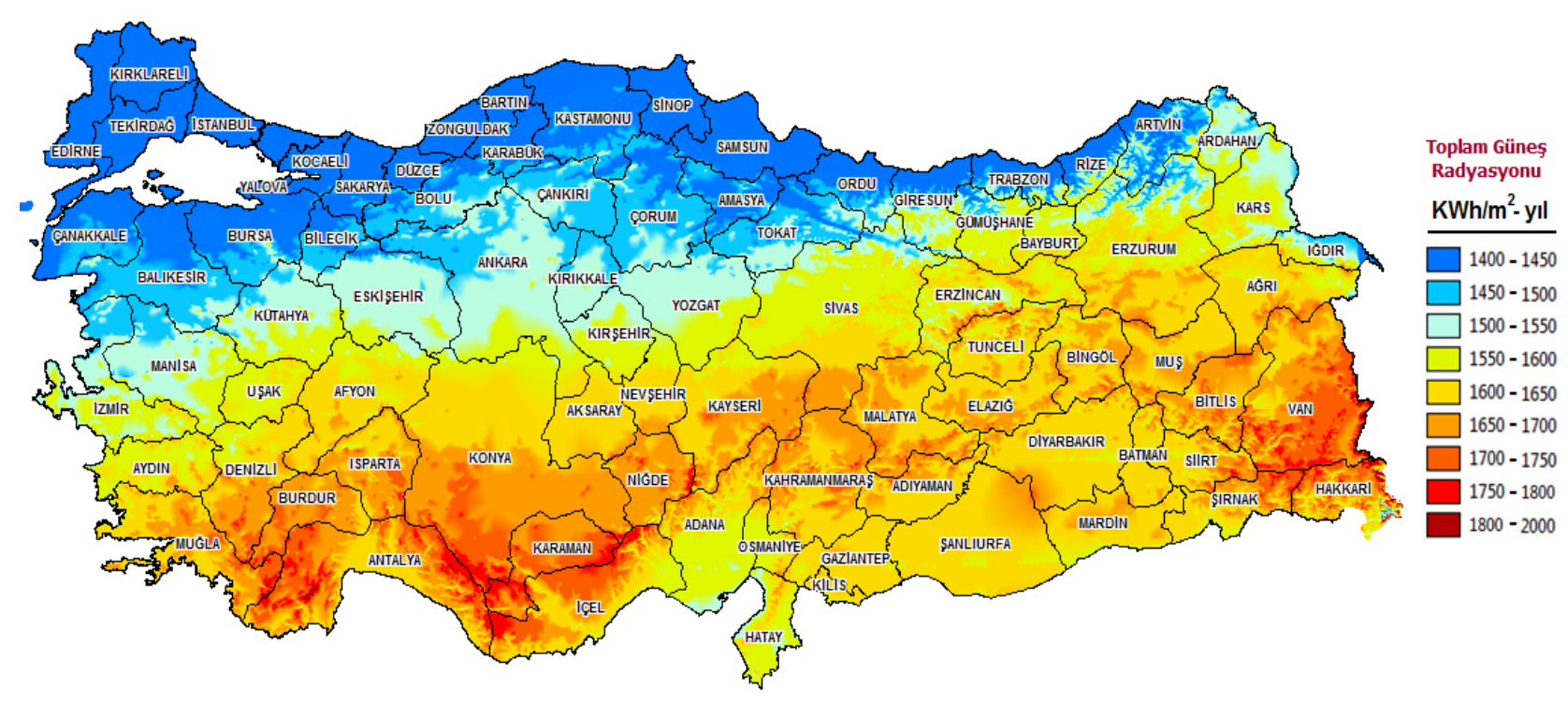

Şekil 1. Türkiye güneş radyasyon haritası 
Türkiye'nin güneş enerjisi potansiyel haritası Şekil 1'de gösterilmiştir. Bu haritaya göre $1 \mathrm{~m}^{2}$ yüzey alanına gelen yıllık ortalama güneş radyasyon miktarı güneye gidildikçe artmaktadır. Türkiye global radyasyon değerleri günlük en fazla $6.570 \mathrm{kWh} \mathrm{m}^{-2}$ ile haziran ayında, 11.31 saat ile en yüksek güneşlenme süresi ise temmuz ayında gerçekleşmektedir (Anonim, 2021). Güneş enerjisinden elektrik üretiminde kullanılan fotovoltaik (PV) sistemler temel olarak ikiye ayrılmaktadır. Bu sistemler şebekeden bağımsız (off grid) ve şebekeye bağlı (on grid) olarak çalışmaktadır. Şebeke elektriğinin olmadığı veya kullanıma uygun olmayan yerlerde elektrik ihtiyacının karşılanması amacıyla şebekeden bağımsız sistemler kullanılmaktadır. Paneller aracılığıyla güneş enerjisinden elde edilen doğru akım ile aküler şarj edilmektedir. Depolanan enerji bir çevirici aracılığıyla alternatif enerjiye çevrilmektedir (Çağlayan ve Ertekin, 2012)

Şebekeye bağımlı sistemlerde üretilen enerjinin tamamı veya fazla gelen elektrik enerjisi şebekeye satılır, yeterli elektrik enerjinin üretiminin gerçekleşmediği durumlarda ise şebekeden enerji alınır. Şebekeye bağı sistemler, akülü ve aküsüz olarak kurulabilmektedirler. Şebeke bağlantılı sistemlerin de kendi içerisinde farklı piyasalarda üç nihai kullanım alanı bulunmaktadır. Bunlar; Konutlarda uygulanan PV sistemler, ticari binalarda uygulanan PV sistemler ve büyük ölçekli PV sistemlerdir. PV sistemlerde (çatı tipi PV sistemler) üretim ile tüketim aynı yerde ise çift yönlü sayaç ile şebekeye bağlantısı sağlanmakta, farklı yerde ise çift sayaç kullanılmaktadır (Cebeci, 2017).

Karaağaç ve ark. (2020) yaptıkları çalışmada, tavuk çiftliği için güneş enerji sisteminin tasarımı ve maliyet analizini araştırmışlardır. Çiftliğin aylık ortalama elektrik tüketimini 2778 kWh ve aylık ortalama elektrik tüketim maliyeti $1290 \mathrm{TL}$, yıllık toplam maliyeti ise $15480 \mathrm{TL}$ olarak bulmuşlardır. Çiftlik çatısına kurulacak olan güneş panel sistemin aylık ortalama üretimini $2875 \mathrm{kWh}$ yıllık ise toplam 34510 kWh hesaplamışlardır. Güneş panellerinin kendini amorti süresini 6 yıl olarak bildirmişlerdir. Emiroğlu ve ark. (2021) yaptıkları çalışmada, Kahramanmaraş ilinde bulunan etlik piliç ve tatlı su balık işletmelerinde şebekeye bağlantılı (On-grid) ve şebekeye bağlantısız (Off-grid) güneş panel sistemlerinin kullanımını araştırmışlardır. Araştırma sonucuna göre $300 \mathrm{kWh}$ kapasiteli etlik piliç işletmesi ve $49 \mathrm{kWh}$ kapasiteli tatlı su balık işletmelerinin 4 ila 5 yıl içerisinde elektrik enerjisi maliyetlerini sıfıra indirdiğini bildirmişlerdir. Ayrıca etlik piliç işletmesinde kullanılan on-grid sistem ürettiği fazla elektriğini şebekeye verdiğinden dolayı bu işletmeden yılda ortalama $312000 \mathrm{TL}$ gelir elde edildiğini açıklamışlardır. Durmaz ve ark. (2017) yaptıkları çalışmada güneş panel sistemlerinin kurulumunun doğru yapılmasının ve içsel tarımsal mekanizasyonda kullanılan enerji tüketimlerinin bilinerek hareket edilmesi durumunda güneş panellerinin tarımsal işletmelerde kullanılabilecek önemli bir enerji kaynağı olduğunu bildirmişlerdir.

Kwaśniewski ve ark. (2020) çalışmalarında, seçilen çiftliklerde fotovoltaik (PV) kurulumları kullanma olasılıklarının ekonomik bir analizini yapmayı amaçlamışlardır. Analiz için seçilen iki çevrimiçi PV hesaplayıcı kullanılmıştır. Araştırma, Małopolskie Eyaletinde bulunan 15 çiftlikte yapılmıştır. Illk hesaplamada, Hewalex kullanılarak tahmin edilen bir PV kurulumu için, geri ödeme süresi, \%40 devlet desteği seçeneği için 5.5 ila 7 yıl ve devlet desteği olmadan 9 ila 11 yıl arasında değiştiğini tespit etmişlerdir. Öte yandan, SmartekDom hesaplayıcısı kullanılarak tahmin edilen geri ödeme süresi, $\% 40$ devlet destekli seçenek için 6 ila 8 yıl arasında olduğunu bulmuşlardır. Ancak, devlet desteği olmadan, süre 7 ila 13 yıl arasında değiştiğini belirlemişlerdir.

Delice ve Yaslıoğlu (2021) yaptıkları çalışmada hayvansal üretim sistemlerinde, işletmeler için önemli bir girdinin elektrik enerjisi maliyeti olduğunu bildirmişlerdir. Bursa ilinde süt sığırcılığı işletmesinde gerçekleştirdikleri çalışmalarında; farklı yönlerden çatıya gelen güneş ışığının elektrik üretimi üzerine etkisini belirlemişlerdir. Çatılara yerleştirilecek panellerin üreteceği elektrik enerjisini PVSOL yazılımı ile belirlemişlerdir. Araştırma sonucuna göre KuzeyGüney (K), Doğu-Batı (E), Kuzeydoğu-Güneybatı (KD) ve Kuzeybatı-Güneydoğu (KB) yönelimli panellerden üretilen elektrik enerjisi en fazla 179.453 kWh ile Kuzey-Güney (K) olduğunu bildirmişlerdir. Hayvansal üretim işletmelerinde önemli bir girdi haline gelen elektrik enerjisinin yenilenebilir enerji kaynaklarından karşılanması maliyetin azaltılması açısından önemli hale gelmiştir.

Bu çalışmada, Konya'da bir hayvan çiftliğinin çatısına yeni kurulan güneş panellerinin uygulanabilirliği ve işletmeye ekonomik getirisinin hesaplanması amaçlanmıştır. Çiftlik çatısında kurulu güneş panellerinin üreteceği elektrik miktarı hem yerinde ölçümlerle hem de European Commission'un geliştirdiği photovoltaic geographical information system ile karşılaştırılmıştır. Aynı zamanda Konya bölgesinde yoğun bulunan büyük baş hayvan çiftliklerinde güneş enerjisine dayalı elektrik üretimi ile ilgili bir çalışma bulunmamaktadır. Bu çalışma diğer bir yandan, yenilenebilir enerji sistemlerinden yararlanmak isteyen özellikle büyük baş hayvan 
çiftliklerinde güneş enerjisi sistemlerinin uygulanmasına yönelik fikir verecektir.

\section{Materyal ve Metot PV tesis tasarımı}

Çalışmada ele alınan özel besi çiftliği işletmesi Konya ili Karatay ilçesinde yer almaktadır. İşletme $33000 \mathrm{~m}^{2}$ alana kurulu ve 380 dekar sulanan tarım arazisine sahiptir. İşletmede dönemsel olarak besi için 300 adet büyük baş hayvan yetiştirilmekte ve mısır silajı, yonca, fiğ, arpa gibi hayvansal yem bitkileri üretimi gerçekleştirilmektedir.

Çalışmada öncelikle, PV sistemi için işletmenin temel elektriksel yükleri belirlenmiştir (Çizelge 1). İşletmenin günlük enerji ihtiyacı 1174.5 kWh, aylık ise 35235 kWh olarak tespit edilmiştir. İşletmenin bir yıllık geriye dönük fatura edilmiş aylık ortalama tüketim değeri 35746 kWh'dır. Buradan işletmede kullanılan makine ve ekipmanların faal olarak kullanıldığı ortaya çıkmaktadır. İşletme sahibi güneş enerjisinden elektrik üretmek için şebekeye bağlı (on grid) PV sistem tercih etmiştir. Yani üretmiş olduğu elektriğin tamamını şebekeye verecek ve ihtiyacı olan elektriği şebekeden alacaktır. Daha sonra aylık olarak ilgili elektrik dağıtım şirketi ile mahsuplaşmaya gidecektir.

İşletmede kullanılan güneş paneline ait teknik özellikler Çizelge 2'de verilmiştir. Konya ilinin güneş ışınım şiddetinin aylara göre değişimi ve ortalama güneşlenme süreleri Çizelge 3'te verilmiştir. Çizelge 3 incelendiğinde Konya ilinde güneş ışınım şiddeti ve güneşlenme süresinin en yüksek olduğu ay Temmuz, en düşük olduğu ay ise Aralık olarak görülmektedir. Besi çiftliğine kurulan güneş enerji santrallerinin 2021 Ağustos kur bilgilerine göre ekipmanların maliyetleri Çizelge 4 'te verilmiştir. Çizelge incelendiğinde en fazla maliyet güneş panellerinde olduğu görülmektedir.

Çizelge 1. İşletmenin temel elektriksel yükleri

\begin{tabular}{llll}
\hline Elektriksel yükler & Gücü $(\mathrm{kW})$ & $\begin{array}{l}\text { Günlük ortalama çalışma } \\
\text { süresi (saat) }\end{array}$ & $\begin{array}{l}\text { Toplam enerji miktarı (kWh } \\
\text { gün }^{-1} \text { ) }\end{array}$ \\
\hline Dalgıç pompa (2 adet) & 75 & 3 & 450 \\
Soğuk hava deposu & 11.5 & 24 & 276 \\
Hidrofor (2 adet) & 5.5 & 16 & 176 \\
Gübre karıştırıcı (2 adet) & 7.5 & 1 & 15 \\
Seperatör & 7.5 & 1 & 7.5 \\
Gübre pompası (2 adet) & 7.5 & 1 & 15 \\
Sıyırıcı (4 adet) & 4 & 4 & 64 \\
Kaşağı (12 adet) & 0.25 & 4 & 12 \\
Elektrikli testere (4 adet) & 7.5 & 0.5 & 15 \\
Diğer (aydınlatma. TV vb) & 12 & 12 & 144 \\
\hline Toplam & 138.25 & & 1174.5 \\
\hline
\end{tabular}

\section{Panel verim ölçümü}

PV sisteminin verim değerini hesaplamak için işletmenin kurulu olduğu yerde ölçümler alınmıştır. Ölçümler 25.09.2021 tarihinde 13.35 yerel saatinde; $30{ }^{\circ} \mathrm{C}$ hava sıcaklığı, \%48 bağıl nem, $2 \mathrm{~ms}^{-1}$ rüzgar hızında ve $740 \mathrm{Wm}^{-2}$ ışıma gücü şartlarında yürütülmüştür. Paneller çatıya $10^{\circ}$ eğim ile yerleştirilmiştir. Ölçümlerde kullanılan cihazlara ait teknik özellikler Çizelge 5'te verilmiştir.

Güneş panelleri tarafından üretilen elektriksel güç, açık devre akım ve kısa devre gerilim değerlerine bağlı olarak Eşitlik 1'e göre hesaplanmıştır (Öztürk ve ark., 2016).

$P P V=10 c \times V s c$

$P P V: P V$ sistem tarafından üretilen elektriksel güç miktarı (W)
Ioc : açık devre akım değeri $(A)$ ve $V s c$ : kısa devre gerilim değeridir (V).

PV sistemin verimi $\left(\eta_{\mathrm{pc}}\right)$, Eşitlik 1'de verilen denkleme göre hesaplanmıştır. Burada verim, sistem tarafından üretilen elektrik miktarının ( $\mathrm{Ppv})$, panellerin yüzey alanına gelen güneş enerjisi miktarına oranıdır. (Öztürk ve ark., 2016).

$\eta_{P V}=\frac{P_{P V}}{I_{t} \times A_{P V}}$

Apv: PV yüzey alanı $\left(\mathrm{m}^{2}\right)$

$\mathrm{I}_{\mathrm{t}}$ : Toplam güneş ışınımı $\left(\mathrm{Wm}^{-2}\right)$

PpV: PV sistemin gücü (W)

$\eta_{\mathrm{PV}}: \mathrm{PV}$ sistem verimidir (\%) 
Çizelge 2. Bir adet güneş paneline ait etiket değerleri

\begin{tabular}{|c|c|c|}
\hline Model No & & CWT450-144PMHCMB \\
\hline Maksimum güç (Wp) & & 450 \\
\hline Maksimum güçte voltaj (V) & & 41.4 \\
\hline Maksimum güçte akım (A) & & 10.87 \\
\hline Açık devre gerilimi (V) & & 49.2 \\
\hline Kapalı devre akımı (A) & & 11.61 \\
\hline \multicolumn{3}{|c|}{$\begin{array}{l}\text { Çizelge 3. Konya ili için radyasyon değerlerinin ve ortalama güneşlenme sürelerinin aylara göre değişimi } \\
\text { (Anonim, 2021) }\end{array}$} \\
\hline Aylar & Radyasyon değerleri (kWh/m²-gün) & Güneşlenme süresi (saat) \\
\hline Ocak & 1.98 & 4.19 \\
\hline Şubat & 2.56 & 5.51 \\
\hline Mart & 4.23 & 6.88 \\
\hline Nisan & 5.20 & 8.03 \\
\hline Mayıs & 6.30 & 9.46 \\
\hline Haziran & 6.78 & 11.28 \\
\hline Temmuz & 6.81 & 11.97 \\
\hline Ağustos & 6.05 & 11.36 \\
\hline Eylül & 5.12 & 9.79 \\
\hline Ekim & 3.73 & 7.35 \\
\hline Kasım & 2.36 & 5.53 \\
\hline Aralık & 1.77 & 3.93 \\
\hline
\end{tabular}

Çizelge 4. Güneş enerjisi santral sisteminin kurulum maliyeti

\begin{tabular}{llll}
\hline GES sistem ekipmanları & Birim & Birim fiyatı (TL) & Toplam maliyeti (TL) \\
\hline Güneş Paneli & 1080 adet & 1350 & 1458000 \\
Invertör & 4 adet & 50000 & 200000 \\
Konstrüksiyon & - & - & 75600 \\
Kablolama & $10000 \mathrm{~m}$ & 9 & 90000 \\
MC4 Konnektör Set & 300 adet & 30 & 9000 \\
Diğer (işçilik, ulaşım vb.) & - & - & 12000 \\
\hline Toplam & & & 1844600 \\
\hline
\end{tabular}

Çizelge 5. Cihazların teknik özellikleri

\begin{tabular}{|c|c|}
\hline Cihaz & Teknik özellikleri \\
\hline Bağıl nem ölçer & $\begin{array}{l}\text { Marka: Hydrotermometer, Tip: PCE } 330 \text {, Ölçüm aralı̆̆ı: } 0-100 \% \text { rh-30 ile } 100^{\circ} \mathrm{C} \text {, } \\
\text { Hassasiyet: } \pm 2.0 \% \text { r.h. } \pm 0.5^{\circ} \mathrm{C} \text {, Batarya: } 9 \mathrm{~V} \text { (PP3) }\end{array}$ \\
\hline Sıcaklık ölçer & $\begin{array}{l}\text { Marka: Extech SDL200, Çözünürlük: } 0.1^{\circ} / 1^{\circ} \text {, Kanal Sayısı: 4, Çalışma Şartları: } 0 \ldots \\
50^{\circ} \mathrm{C},<85 \% \mathrm{RH} \text { (yoğuşmasız) }\end{array}$ \\
\hline Anemometre & 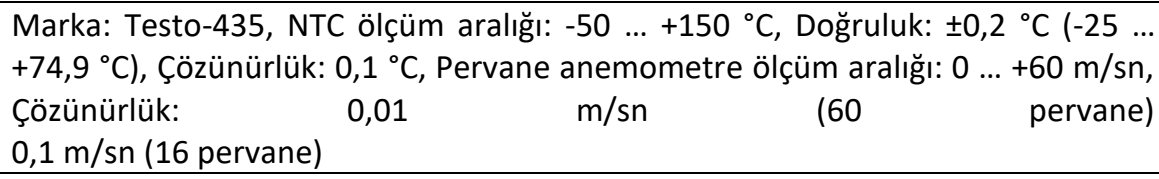 \\
\hline Solar güç ölçer & Marka: TES-1333R, Ölçüm aralığı: $2000 \mathrm{~W} / \mathrm{m}^{2}$, Hassasiyet: $0.1 \mathrm{~W} / \mathrm{m}^{2}$ \\
\hline Pensampermetre & $\begin{array}{l}\text { AC Akımı: } 600 \mathrm{~A} \pm(\% 2+10), \text { AC Akım Frekansı : } 50 \mathrm{~Hz} \sim 100 \mathrm{~Hz} \pm(\% 1+5), \mathrm{AC} \\
\text { Voltajı : } 600 \mathrm{~V} \pm(\% 0.8+5), \mathrm{AC} \text { Voltaj Frekansı: } 10 \mathrm{~Hz} \sim 10 \mathrm{kHz} \pm(\% 1+5), \mathrm{DC} \\
\text { Voltajı: } 600 \mathrm{~V} \pm(\% 0,5+2) .\end{array}$ \\
\hline
\end{tabular}




\section{Bulgular ve Tartışma}

\section{Güneş enerjisi sisteminin elektrik üretimi}

İ̧̧letmenin çatısına kurulan güneş enerjisi sisteminin aylara göre üretilecek elektrik hesaplamaları iki farklı yönteme göre yapılmışır. Birinci yöntemde Eşitlik 1 ve 2'ye göre hesaplanan bir panele ait verim değerlerinden ve bölgenin güneşlenme süresinden yola çıkılarak hesaplama yapılmıştır. Saha ölçümleri sırasında bir panelden ölçülen açık devre akım değeri $5.98 \mathrm{~A}$, kısa devre gerilim değeri $42.2 \mathrm{~V}$ ve panel yüzey sıcaklığı $36^{\circ} \mathrm{C}$ olarak ölçülmüştür. Bir adet panelden alınan elektrik enerjisi $252 \mathrm{~W}$ ve verim değeri \%15.5 olarak hesaplanmıştır. İşletmenin kurulu olduğu bölgenin aylık güneşlenme süresi dikkate alındığında güneş enerjisi sisteminin üreteceği elektrik hesaplanan üretim değeri olarak Şekil 2'de verilmiştir.

Güneş enerji sisteminin aylara göre üreteceği elektrik hesaplamasında ikinci yöntem olarak ise European Commission'un geliştirdiği photovoltaic geographical information system ile yapılmıştır (Karaağaç ve ark., 2020; Anonim, 2021b). Bu iki yöntemden elde edilen değerlerin karşılaştırmaları Şekil 2'de verilmiştir. İşletmenin en fazla enerji üretimi her iki yöntemde de temmuz ayında gerçekleşmiştir. Birinci ve ikinci yöntemlere göre güneş enerjisi sisteminden 1 yıl boyunca ortalama aylık enerji üretim değerleri sırasıyla $64031 \mathrm{kWh}$ ve $66502 \mathrm{kWh}$ gerçekleşmesi beklenmektedir. Yöntemler arasındaki üretim değerleri farkı 2471 kWh olarak hesaplanmıştır.

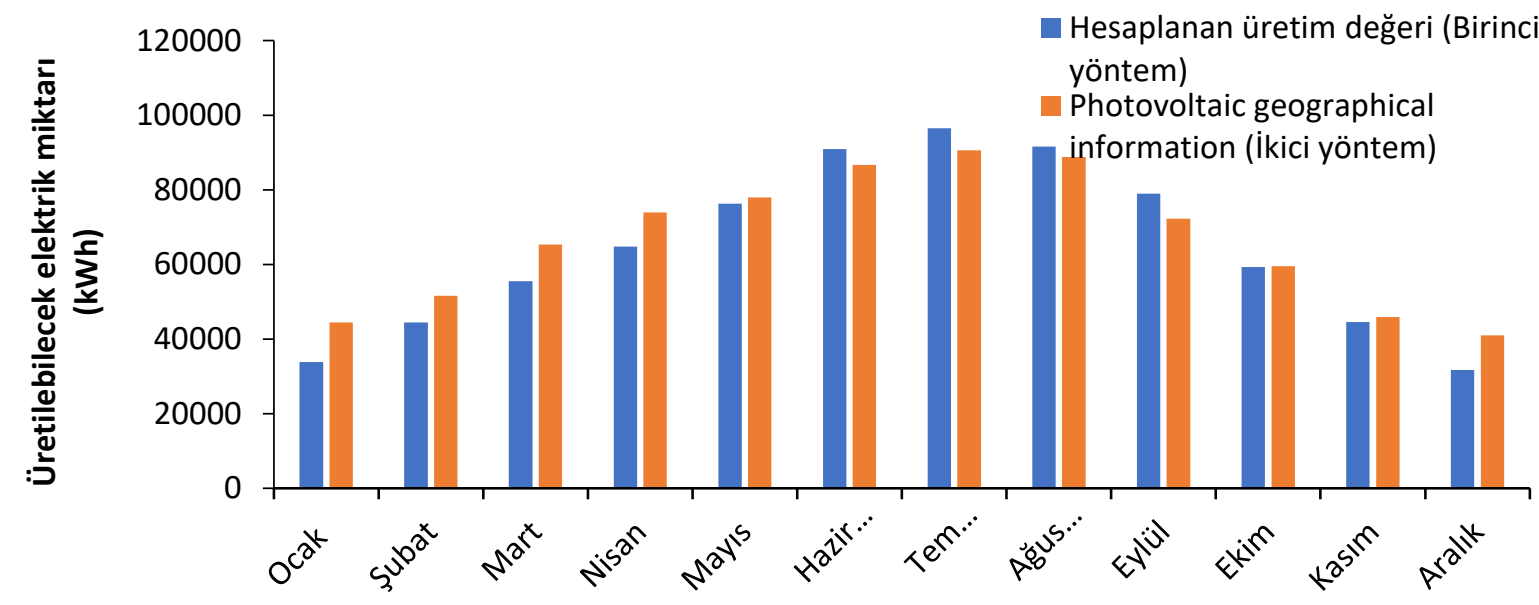

Şekil 2. Fotovoltaik panellerden üretilen elektrik miktarlar

\section{Işletmenin elektrik üretim ve tüketim değerlerine ait maliyet analizi}

Çizelge 6 'da 491.4 kW gücündeki çatı güneş enerji sistemli işletmenin elektrik üretim ve tüketim değerlerine ait maliyet analiz değerleri verilmiştir.

Sistemin toplam kurulum maliyeti 1844600 TL'dir. Yatırım maliyetinin \%79'u PV paneller oluşturmaktadır. Panellerin Watt başına maliyeti 3 $\mathrm{TL}$, sistem maliyeti ise $3.79 \mathrm{TL}$ 'dir. Güneş enerjisi sisteminin yıllık elektrik üretim miktarı işletmenin yıllık ortalama elektrik tüketim miktarından 369072 kWh fazla çıkmıştır. İşletmenin fatura edilmiş aylık ortalama 35746 kWh elektrik tüketim değerini, günümüz şartlarında işletmeler için $0.78 \mathrm{TL}$ olan elektrik birim fiyatından hesaplandığında aylık ortalama elektrik tüketimi 27881 TL'dir. İşletmenin yıllık ortalama elektrik tüketimi 334582 TL'dir. PV sisteminin aylık elektrik üretim miktarı 66502 kWh, yıllık üretimi ise 798024 kWh olmaktadır. Güneş enerji sistemi için işletmenin şebekeye sattığı elektrik fiyat $0.32 \mathrm{TL} / \mathrm{kWh}$ 'dır. Bu durumda PV sisteminin üretmiş olduğu elektrikten ortalama yıllık kazancı 255368 TL'dir.
Modül imalatçıları PV sistemlerinin garanti sürelerini dikkate alarak ekonomik ömürlerini genellikle 20-25 yıl arasında almaktadır (Ondraczek, 2014). Yapılan araştırmalar, PV sistemin ekonomik ömrünün 40 yıla, kristal silikon teknolojisinde 50 yıla kadar yükselebileceğini göstermektedir (Bazilian ve ark., 2013). Bu çalışma için PV güneş enerjisi sisteminin ekonomik ömrü 25 yıl varsayılmıştır (Akyüz ve ark., 2009). Ayrıca, PV sistemlerinde kullanılan panellerde her yıl $\% 0.30$ 'lük verim düşüşü gözlemlenmiş ve üretim değerinin yıldan yıla düştüğü bildirilmiştir (Taktak ve Mehmet, 2018). Bu bağlamda güneş enerjisi sisteminin kendini amorti etmesi 7.2 yıl olarak hesaplanmıştır. Karaağaç ve ark. (2020) tavuk çiftliği için yaptıkları çalışmada çatı tipi güneş enerji sisteminin kendini amorti süresini 6.2 yıl olarak bildirmişlerdir. Atakul ve ark. (2015) yaptıkları çalışmalarında $250 \mathrm{kWp}$ gücüne sahip güneş enerjisi santralinin 6 yılda kendini amorti edeceğini açıklamışlardır. Güneş enerjisi sisteminin kendini amorti etme süresinin diğer çalışmaların yarısına yakın olmasında kullanılan panelin gücü ve bölgesel iklim şartları etkili olmuştur. 
Çizelge 6. İşletmenin elektrik üretim ve tüketimine yönelik maliyet analizi

\begin{tabular}{ll}
\hline Panel maliyeti (TL/W) & 3 \\
Sistem maliyeti (TL/W) & 3.79 \\
Yıllı üretim zamanı & 2858 saat \\
İşletmenin aylık ortalama elektrik tüketimi (kWh) & 35746 \\
İşletmenin yıllık ortalama elektrik tüketimi (kWh) & 428952 \\
Şebekeden çekilen elektrik birim fiyatı (TL/kWh) & 0.78 \\
İşletmenin yıllık ortalama elektrik tüketim maliyeti (TL) & 334582 \\
*Işsletmenin 10 yıllık ortalama elektrik tüketim maliyeti (TL) & 3334582 \\
PV sisteminin aylık ortalama elektrik üretimi (kWh) & 66502 \\
PV sisteminin yıllık üretim miktarı (kWh) & 798024 \\
PV elektrik üretim alım fiyatı (TL/kWh) & 0.32 \\
PV sistemin yıllık elektrik üretim kazancı (TL) & 255368 \\
*PV sisteminin 10 yıllık elektrik üretim kazancı (TL) & 2255368 \\
\hline *Alım garantisi 10 yı üzerinden yapıldığı çin hesaplamalarda 10 yıllık tüketim ve üretim fiyatları verilmiştir &
\end{tabular}

\section{Güneş Enerjisi Sisteminin Çevresel Etkisi}

Türkiye'de elektrik enerjisi toplam kurulu gücün \%20.6'sı kömürden üretilmektedir. Türkiye de kömür ile çalışan kurulu termik santrallerin yıllık elektrik üretimi ortalama 107567 GWh'dır. Bu termik santraller kömürden elektrik üretebilmek için atmosfere $\mathrm{CO}_{2}$ salmaktadır. Termik santrallerin $1 \mathrm{kWh}$ elektrik enerjisi üretebilmek için atmosfere $0.94 \mathrm{~kg} \mathrm{CO} 2$ gazı salındığı (Karaağaç ve ark., 2020) göz önüne alındığında bu santraller yılda yaklaşık 100 milyon ton $\mathrm{CO}_{2}$ salmaktadır. $\mathrm{Bu}$ durumda atmosfere salınan yüksek miktarda karbondioksit miktarını azaltmanın en önemli yolu yenilenebilir enerji kaynaklarına yönelmektir. Bu çalışma kapsamında değerlendirilen işletmeye kurulan güneş enerji sisteminin yıllık elektrik üretim miktarının 798024 kWh olduğu göz önüne alındığında $750142 \mathrm{~kg} / \mathrm{yıl} \mathrm{CO}$ salınımı engellenmiş olmaktadır.

\section{Sonuç ve Öneriler}

Büyük bir yenilenebilir enerji potansiyeline sahip olan Türkiye'de özellikle güneş enerjisi kullanımının yaygın hale getirilmesi gerekmektedir. $\mathrm{Bu}$ bağlamda bitkisel ve hayvansal üretim gerçekleştiren ve hızla büyüyen büyükbaş, küçükbaş, kanatlı vb. hayvan çiftlikleri, güneş enerjisinin kolaylıkla uygulanabileceği tesislerdir. $\mathrm{Bu}$ çiftliklerde en başta gelen girdi maliyetlerinin biri de elektrik enerjisidir. Bu çalışmada, artan bu elektrik ihtiyacımızı karşılamak için Konya'da, orta ölçekli bir büyük baş hayvan çiftliğinde güneş enerjisinin uygulanabilirliği ve işletmeye getirisinin hesaplanması amaçlanmıştır.

İşletmenin çatısına kurulan güneş enerji sisteminin toplam maliyeti $1884600 \mathrm{TL}$ hesaplanmıştır. İşletmenin aylık elektriksel yükü 35746 kWh olarak belirlenmiştir. Bu elektriksel yükün \%38.3'ünü tarımsal sulama için kullanılan 75 kW gücünde 2 adet dalgıç pompa oluşturmaktadır.
Besi çiftliği işletmesi için aylık ortalama elektrik tüketim maliyeti $27881 \mathrm{TL}$, yıllık ise $334582 \mathrm{TL}$ hesaplanmıştır. Güneş enerji sisteminin aylık elektrik üretim miktarı $21280 \mathrm{TL}$, yıllık ise 255368TL'dir. Güneş enerji sistemi ürettiği elektriği direk şebekeye sattığı ve tüketim için direk şebekeden aldığı için batarya ücreti ve yenileme gibi sorunu olmayacaktır. Bu durumda sistemin kendini amorti süresi yaklaşık 7.2 yıl olarak hesaplanmıştır. Güneş enerji sistemlerinin 25 yıl ortalama ömrü olduğunu hesaba katarsak geriye kalan 17.8 yıl sonunda işletmenin maliyetlerinde güncel elektrik alım fiyatı ile hesaplandığında yaklaşık olarak 4.5 milyon TL azalmanın olacağı tahmin edilmektedir. Ayrıca, işletmenin güneş enerji sistemi ile temiz enerji üretimi sayesinde, yıllık elektrik tüketim değerine eşdeğer 750142 kg $\mathrm{CO}_{2}$ salınımı engellenmiş olacaktır. $\mathrm{Bu}$ işletme için güneş enerjisi sisteminin ekonomik bir yatırım olmasının yanı sıra elektrik üretimi bakımından $\mathrm{CO}_{2}$ salınımına sebep olmaması büyük bir avantajdır.

Tarımsal faaliyet gösteren işletmeler için en büyük girdilerden biri olan elektrik enerjisini güneş enerji sistemleri ile karşılamak hem işletmelerin maliyetini düşürecek hem de tüketiciler için uygun alım fiyatlarına imkan sağlayacaktır. Bu ve benzeri alanda faaliyet gösteren işletmelerin yenilenebilir enerji kullanım alanlarını genişletmelerine imkan sağlamak, gerekli destekleri artırmak tarımsal faaliyetlerin sürdürebilirliği için önemli olacaktır.

Çıkar Çatışması Beyanı: Makale yazarları aralarında herhangi bir çıkar çatışması olmadığını beyan ederler.

Araştırmacıların Katkı Oranı Beyan Özeti: Yazarlar makaleye eşit oranda katkı sağlamış olduklarını beyan ederler. 


\section{Kaynaklar}

Aksungur, K. M., Kurban, M. ve Filik, Ü., 2013, Türkiye'nin Farklı Bölgelerindeki Güneş Işınım Verilerinin Analizi ve Değerlendirilmesi, Enerji Verimliliği ve Kalitesi Sempozyumu, 23-24 Mayıs, Kocaeli.

Akyüz, E., Bayraktar, M. ve Oktay, Z., 2009, Hibrid yenilenebilir enerji sistemlerinin endüstriyel tavukçuluk sektörü için ekonomik açıdan değerlendirilmesi: Bir uygulama, Balıkesir Üniversitesi Fen Bilimleri Enstitüsü Dergisi, 11 (2), 44-54.

Anonim, 2021a, Güneş Enerjisi Potansiyel Atlası. www.eie.gov.tr (erişim tarihi: 25.09.2021).

Anonim, 2021b, European Commission, Photovoltaic Geographical Information System [Online]. Erişim tarihi: 26.09.2021, http://re.jrc.ec.europa.eu/pvg_tools/en/too Is.htm,

Atakul, Ş., Ali Kalender, M., Gezici, M. ve Eliçin, A. K., 2015, Güneş Tarlası Kurulumu, Tarım Makinaları Bilimi Dergisi, 11 (1), 55-60.

Bazilian, M., Onyeji, I., Liebreich, M., MacGill, I., Chase, J., Shah, J., Gielen, D., Arent, D., Landfear, D. ve Zhengrong, S., 2013, Reconsidering the economics of photovoltaic power, Renewable Energy, 53, 329-338.

Cebeci, S., 2017, Türkiye'de güneş enerjisinden elektrik üretim potansiyelinin değerlendirilmesi, Uzmanlık Tezi, İktisadi Sektörler ve Koordinasyon Genel Müdürlüğü, Kalkınma Bakanlığı, Yayın (2977).

Çağlayan N; Ertekin C, 2012, Güneş Enerjili Elektrik Güç Sistemlerinin Tarımsal Alanlardaki Uygulamaları Üzerine Bir Fizibilite Çalışması: Tavuk Çiftliği Uygulaması. 27. Tarımsal Mekanizasyon Ulusal Kongresi. 5-7 Eylül, Samsun, s.100-108.

Delice, H. ve Yaslıoğlu, E., 2021, The Effect of Building Orientation on Utilization of Solar Energy in Dairy Cattle Barns, Tekirdağ Ziraat Fakültesi Dergisi, 18 (3), 419-427.

Durmaz, F., Akdeniz, R. C. ve Kömekçi, F., 2017, Fotovoltaik Enerji ile Tarımsal İşletmelerin Enerji Gereksiniminin Karşılanabilirliği:
Manisa-Turgutlu Örneği, Tarım Makinaları Bilimi Dergisi, 13 (3), 193-199.

Emiroğlu, F., Aybek, A. ve Hamza, K., 2021, İki farklı fotovoltaik (PV) enerji sisteminin farklı hayvancılık işletmelerinde kullanımının değerlendirilmesi, Mustafa Kemal Üniversitesi Tarım Bilimleri Dergisi, 26 (3), 808-820.

Güler, S., 2014, Orta ölçekli hayvancılık işletmelerinde yenilenebilir enerji kullanım olanakları ve örnek bir uygulama, Yüksek Lisans Tezi, Namık Kemal Üniversitesi, Fen Bilimleri Enstitüsü, Biyosistem Mühendisliği Anabilim Dalı, Tekirdağ.

Hakyemez, C., 2021, Aylık Enerji Bülteni, TSKB Danışmanlık Hizmetleri https://www.tskb.com.tr/i/assets/documen t/pdf/enerji-bulteni-agustos-2021.pdf:

Karaağaç, M. O., Oğul, H. ve Bardak, S., 2020, Kanatlı hayvan çiftliği için güneş enerji sisteminin tasarımı ve maliyet hesabı, Düzce Üniversitesi Bilim ve Teknoloji Dergisi, 8 (1), 711-722.

Kwaśniewski, D., Akdeniz, C., Durmaz, F. ve Kömekçi, F., 2020, Economic analysis of the photovoltaic installation use possibilities in farms, Agricultural Engineering, 24.

Ondraczek, J., 2014, Are we there yet? Improving solar PV economics and power planning in developing countries: The case of Kenya, Renewable and Sustainable Energy Reviews, 30, 604-615.

Öztürk, H., Yaşar, B. ve Eren, Ö., 2010, Tarımda enerji kullanımı ve yenilenebilir enerji kaynakları, TMMOB Ziraat Mühendisleri Odası Türkiye Ziraat Mühendisliği VII. Teknik Kongresi Bildiriler Kitabı,11-15 Ocak, Ankara, s.909-932.

Öztürk, H. H., Küçükerdem, K. ve Gökalp, Y., 2016, Tarımsal Sulamada Güneş Enerjisi Kullanımı Üzerine Bir Araştırma, International Multidisciplinary Congress of Eurasia, 11-12 Eylül, Odessa, Ukrayna, s. 415-421.

Taktak, F. ve Mehmet, I., 2018, Güneş Enerji Santrali (GES) Geliştirme: Uşak Örneği, Geomatik, 3 (1), 1-21. 